\title{
Jaime Eyzaguirre
}

El Instituto de Estudios Internacionales de la Universidad de Chile no puede permanecer silencioso ante el desaparecimiento prematuro de una de las figuras más sobresalientes de nuestra comunidad universitaria. Mayor razón tiene nuestra institución para manifestar su pesar, si se tiene en cuenta que Jaime Eyzaguirre comenzaba, precisamente en estos dias a honrarnos con su inapreciable colaboración. Su actitud para con nosotros fue la que era habitual en él frente a las ideas nuevas cuando ellas se encontraban inspiradas en desinteresados propósitos del amor a la ciencia y de servicio al pais.

Tuve el honor de conocerlo bien porque fui su alumno y como tal pude ser distinguido con su valiosa amistad. El magisterio del Profesor Eyzaguirre estaba inspirado por aquellas excepcionales virtudes que distinguen a ciertos hombres y que los elevan a la categoria de formadores de juventud. Porque existe una linea indefinible, y que los jóvenes conocen muy bien, que separa al hombre que es sólo un buen informador de aquel que efectivamente puede ser distinguido con el titulo de maestro. El era de estos últimos. Para él nunca hubo diferencia de importancia en las personas ante quienes enseñaba, sus clases nunca fueron improvisación, cualquiera que fuera la categoria intelectual del auditorio. Es por eso que mi primer contacto con él quedó grabado para siempre en mi memoria y fue decisivo en mi vocación y en el curso de mi vida. Esto ocurrió hace ya muchos años en el patio de un liceo en que yo cursaba mis humanidades y al que el profesor habia sido invitado a dar una charla sobre la historia de Chile. Su versión era tan original, tan viva, $\tan$ novedosa y apasionante que el impacto que produjo en los que escuchábamos no pudo ser olvidado en los años que vinieron.

Pasó el tíempo e ingresé a la Escuela de Derecho de la Universidad de Chile. El calor humano es muy dificil de alcanzar cuando uno ingresa a una Facultad de Ciencias Juridicas. El peso de la norma es tan grande que ella se convierte en suprema dictadora de los hombres. Deja de ser un instrumento al servicio de la felicidad humana para convertirse en dogma indiscutido e indiscutible. A partir de ella se construyen enormes sistemas que a la manera de telarañas lo cubren todo. Toda crítica, toda objeción debe ser hecha dentro del sistema y con los mecanismos que contemplá el sistema, nunca désde fuera. El hombre creador de todo esto no puede controlarlo. Frente al valor de la justicia se levanta otro más poderoso que se llama orden. Nunca fue esa manera de pensar la aceptada por él y sus cátedras de.Historia Constitucional e Historia del Derecho siempre estuvieron orientadas a demostrarlo. La norma no valia para él por si misma sino en cuanto instrumento creado para la realización de valores. Habia por lo tanto que desentrañar el contenido histórico del Derecho, explorar en el pasado para determinar como los hombres, las ideas y los acontecimientos modelaban el contenido de aquel conjunto de principios reguladores de la conducta. 
No compartia su opinión acerca de la historia y asi se To manifeste en numerosas oportunidades, lejos de ser ese un motivo de alejamiento constituia para él un aliciente del diálogo. Nunca fue enemigo del que no pensabá cómo él, sólo le irritaba el que no pensaba..Sus alumnos siempre tuvimos la oportunidad de llegar hasta él, de contar con su ayuda, de ensayar por nosotros mismos bajo su tutela. El método activo de enseñanza, del que tanto se ha hablado, fue puesto en práctica en sus cátedras mucho antes de su institucionalización, p.es la buena docencia no se impone por decreto, ella existe en la medida en que existe el profesor ágil, imaginativo, desinteresado y sobre todo consagrado a su deber. El era maestro mucho más allá del lapso cronológico de sus clases, el diálogo seguia en los pasillos, en el patio o en cualquier parte. Su casa y su biblioteca estaban abiertas para todo el que lo pidiera.

Me consta personalmente su preocupación porque los estudios de Derecho evolucionasen hacia nuevos cursos y orientaciones. Como cualquiera de nosotros se sentó a deliberar y a participar en debates estudiantiles avocados al problema.

A partir del año 1966 se inició en la Facultad de Ciencias Juridicas y Sociales de la Universidad de Chile la implantación progresiva de un plan renovado de estudios, tanto en el contenido comó en la forma de enseñar. El profesor Jaime Eyzaguirre, junto con un grupo distiiguido de colaboradores compuesto de los Sres. Fernando Silva, Patricio Estellé, Carlos Ugarte y Horacio Aránguiz lo pusieron en práctica en la nueva cátedra de Historia de las Instituciones Politicas y Sociales de Chile. El resultado de la labor de investigación del equipo es un macizo volumen titulado Estudios de Historia de las Instituciones Politicas y Sociales de Chile en el que el extinto incluye un magnifico estudio sobre "Intento de negociación chileno boliviana de 1950 y su secuela". Este trabajo nos fue entregado por el profesor Eyzaguirre pocas semanas antes de su muerte para que nuestra revista hiciera un comentario. Creemos un deber rendir un póstumo homenaje al maestro a través de la mención de ese esfuerzo colectivo. La vanidad, que corrientemente empaña la vida de los hombres que han conocido el éxito, está lejos de esta obra en la que el nombre del profesor Eyzaguirre aparece como uno más de un conjunto de colaboradores. El sumario revela un conjunto de temas de gran interés para nuestra cultủra y un esfuerzo auténtico por interpretar nuestra realidad cientificamente.

El 7 de octubre próximo el Instituto de Estudios Internacionales se preparaba para recibir con orgullo la visita del distinguido profesor quien iba a dirigir un Seminario de trabajo sobre Titulos históricos de Chile en el desierto de Atacama. El infortunio no lo ha permitido sin embargo. Su recuerdo y su ejemplo vivirá para siempre con nuestra institución. 